\title{
Influências das Condições e Organização do Trabalho de uma Indústria de Transformação de Cana-de-Açúcar na Ocorrência de Acidentes de Trabalho
}

Influences of Working Conditions and Organization in a Sugar Cane Transformation Industry in the Event of Accidents at Work

\author{
Cassiano Ricardo Rumin \\ Psicólogo, Mestre em Ciências Médicas. Professor e Supervisor de \\ estágio em Saúde do Trabalhador das Faculdades Adamantinenses \\ Integradas (FAI). \\ Endereço: Rua Nove de Julho, 730, CEP 17800-000, Adamantina, \\ SP, Brasil. \\ E-mail: cassianorumin®fai.com.br \\ Maria Luiza Gava Schmidt \\ Psicóloga, Psicodramatista. Pós-Doutorado em Saúde Ambiental, \\ Professora e supervisora de estágio do Departamento de Psicologia \\ Experimental e do Trabalho da UNESP/Assis. \\ Avenida Dom Antonio, 2100, CEP 19806-900, Assis, SP, Brasil. \\ E-mail: mlschmidtðuol.com.br
}

\section{Resumo}

Este estudo discute a relação entre as condições e a organização do trabalho como elementos que contribuem para a ocorrência de acidentes do trabalho. Os dados foram coletados em uma indústria produtora de açúcar, álcool e derivados, situada no Estado de São Paulo. Para a coleta dos dados utilizamos a observação direta do trabalho e realizamos entrevistas semidirigidas individuais como 22 trabalhadores do setor de produção de açúcar. A produção de açúcar foi indicada pela Equipe de Segurança e Higiene no Trabalho como o setor em que havia a maior ocorrência de acidentes. Por destacar o papel que a relação homem-trabalho desempenha na saúde física e psíquica dos trabalhadores, utilizamos a Psicodinâmica do Trabalho (Dejours, 1994) como referencial teórico para a análise dos dados obtidos nas entrevistas. A análise das entrevistas envolveu três aspectos: condições e organização do trabalho e insatisfação. Os resultados revelaram que o ambiente estudado apresenta fatores físicos, químicos e biológicos desfavoráveis à saúde dos trabalhadores. Quanto à organização do trabalho, os dados revelaram que a divisão do trabalho bem como o conteúdo das tarefas determinavam sobrecarga aos trabalhadores. 0 relato sobre a insatisfação envolveu: ausência de perspectiva para progressão profissional, falta de treinamento técnico, dificuldade em manejar equipamentos e inadequação dos equipamentos de proteção. Destaca-se também no discurso dos trabalhadores a ineficiência das ações organizacionais para a eliminação ou a neutralização dos riscos de acidentes do trabalho e a 
predominância da teoria do "Ato inseguro" na apuração da causalidade dos acidentes do trabalho.

Palavras-chave: Saúde do trabalhador; Acidentes do trabalho; Cana-de-açúcar.

\section{Abstract}

The present study is about the relationship between the work conditions and organization as elements that contribute to work accidents. The data were collected in a sugar cane industry that produces sugar, alcohol and other derivates located in the State of São Paulo. For data collection we have used direct observation of work and conducted semi-directed personal interviews with 22 workers from the sugar production division. Sugar production was indicated by the Work Safety and Hygienic Team as the section where most accidents occurred. We have used the Psychodynamics of the work view (Dejours, 1994) as the theoretical framework to assess data obtained in the interview because it highlights the role the men-work relationship plays in the physical and psychological health of workers. The interviews analysis involved three aspects: working conditions, working organization and dissatisfaction. Results showed that the studied environment presents physical, chemical and biological factors that are unfavorable to workers' health. As for the working organization, data showed that the working division, as well as the tasks overloaded workers. Reports on dissatisfaction involved: lack of perspective of professional development, lack of technical training, difficulty in dealing with equipment and inappropriate protection equipment. In the workers' speech one can stand out the inefficiency of the organizational actions to eliminate or neutralize the working accident's risks and the prevalence of the "Unsafe Act" theory in the investigation of the working accidents' cause.

Keywords: Worker's Health; Occupational Accidents; Sugarcane.

\section{Introdução}

As agroindústrias de cana-de-açúcar têm papel de destaque no Brasil por sua contribuição à indústria alimentícia, por figurar como elemento de destaque na política energética do país, pelo volume financeiro mobilizado em suas atividades e por contribuir com a oferta de postos de trabalho. Para ilustrar essas situações, destacamos a produção das 360 agroindústrias brasileiras de cana-de-açúcar que atingiram 26,2 milhões de toneladas de açúcar e 15,8 milhões de $\mathrm{m}^{3}$ de álcool na safra 2005/2006 (Brasil, 2007).

O estado de São Paulo é o maior estado produtor de açúcar e álcool do Brasil. Na safra 2005/2006, contando com a operação de suas 168 unidades produtivas, foi responsável por aproximadamente $64 \%$ da produção de açúcar e 63\% da produção de álcool do Brasil (União da Agroindústria Canavieira, 2007).

O dinamismo financeiro característico da canavicultura brasileira contrapõe-se ao processo de ocupação de mão-de-obra que, historicamente, sempre contou com a exposição de trabalhadores rurais a condições degradantes de trabalho na colheita manual de canade-açúcar e nos tratos culturais de canaviais (Alessi e Navarro, 1997; Silva, 1999; Gomes e col., 2001; Thomaz Junior, 2002; Rumin, 2004).

No caso dos trabalhadores envolvidos diretamente com a atividade industrial de transformação da canade-açúcar, verificamos a escassez de estudos que apontem as condições de trabalho e as fontes de agravo à saúde. Pinheiro e Ruffino Netto (1994) buscaram preencher essa lacuna na produção de conhecimento sobre a exploração do trabalho na transformação da cana-de-açúcar e identificaram "fatores de insalubridade e periculosidade" a que estão expostos esses trabalhadores. Destacaram como componentes do desgaste à saúde "a realização de um rigoroso trabalho coordenado, onde ocorre um movimento intenso e ininterrupto de matéria-prima e de trabalhadores, executando operações cíclicas, complexas, que exigem coordenação motora precisa, atenção, ritmo acelerado e comunicação simultâneos, mediadas por um sistema de controle manual ou mecanizado sobre máquinas e outros instrumentos de trabalho" (Pinheiro e Ruffino Netto, 1994, p. 42).

Apesar de a contribuição de Pinheiro e Ruffino Netto (1994) abordar o desgaste à saúde dos trabalha- 
dores envolvidos na transformação da matéria-prima, não encontramos referências sobre a ocorrência de acidentes do trabalho nessa atividade.

De acordo com informações estatísticas do Ministério da Previdência e Assistência Social, em 2000 - mesmo período de realização dessa pesquisa de campo -, foram notificados no Brasil 14.273 acidentes do trabalho (AT) nas atividades rurais e industriais de transformação de cana-de-açúcar. Desses, 58,5\% ocorreram nas atividades de cultivo da cana-de-açúcar; $29,9 \%$, na produção de açúcar e 11,6\%, na produção de álcool. Nesse mesmo ano os ATs nas agroindústrias de cana-de-açúcar do estado de São Paulo totalizaram 8.175 ocorrências. Isso representou a proporção de $57,3 \%$ dos ATs que ocorreram nessa atividade econômica em todo o país. As atividades de cultivo de canade-açúcar no estado de São Paulo acumularam 73,2\% dos ATs, a produção de açúcar determinou 19,5\% das notificações e $7,3 \%$ dos eventos de ATs ocorreram na produção de álcool (Brasil, 2002).

De acordo com Teixeira e Freitas (2003), entre 1997-1999, nas usinas de açúcar ocorreram 999 ATs e na produção de álcool, 1.118. Essas duas atividades em conjunto produziram 4,1\% dos acidentes nas atividades rurais do estado de São Paulo. Somados aos 14.661 ATs registrados no cultivo e colheita da cana-de-açúcar que representaram $25,5 \%$ dos acidentes nas atividades rurais do estado de São Paulo totalizaram quase um terço dos ATs ocorridos em atividades rurais em todo estado de São Paulo com a proporção de 29,6\%.

Nesse sentido, esta pesquisa tem o intuito de contribuir com a produção científica sobre os agravos à saúde dos trabalhadores em indústria de transformação da cana-de-açúcar, apresentando diversos aspectos relacionados à ocorrência e à apuração de causas de acidentes do trabalho numa indústria de açúcar e álcool.

\section{Objetivos}

A apresentação dos dados desta pesquisa tem como objetivo discutir como os aspectos das condições e organização do trabalho podem influenciar as ocorrências de acidentes de trabalho. Buscamos também contribuir com informações sobre o processo saúde-doença que envolve a cadeia de transformação da cana-de-açúcar e apresentar um estudo técnico-científico no campo da Saúde no Trabalho.

\section{Materiais e Método}

\section{Contexto}

Os dados foram coletados em uma agroindústria de açúcar, álcool e derivados, situada no estado de São Paulo, na região Sudeste do Brasil. Esse estado brasileiro concentra a maior produção de derivados de cana-deaçúcar do país. A escolha da indústria de transformação para a realização da pesquisa ocorreu, sobretudo, em razão da relevância desse setor na mobilização de mão-de-obra em sua localidade de origem.

\section{Procedimentos de coleta de dados}

A coleta de informações foi realizada por meio de dois instrumentos: observações do ambiente de trabalho e entrevistas semidirigidas com um grupo de 22 trabalhadores de diferentes funções na produção de açúcar e álcool.

Bleger (1990) indica que a entrevista semidirigida é uma técnica que permite a realização de diagnósticos. A resposta ao conteúdo estruturado desta técnica de entrevista permite ao pesquisador preencher alguns objetivos de seu estudo. A entrevista semidirigida permite ao pesquisador conhecer a "descrição subjetiva do trabalho", ou seja, o trabalho reconstituído a partir da elaboração da vivência cotidiana dos trabalhadores (Dejours, 2001).

\section{Sujeitos}

Participaram deste estudo trabalhadores que atuavam diretamente nos processos industriais, excetuando-se os trabalhadores envolvidos no plantio, colheita e transporte da matéria-prima, pois eles estariam expostos a riscos ocupacionais e cargas de trabalho diferenciadas (Alessi e Navarro, 1997; Silva, 1999; Gomes e col., 2001; Thomaz Júnior, 2002; Rumin, 2004).

\section{Análise de dados}

0 referencial teórico escolhido para a análise das entrevistas foi a Psicodinâmica do Trabalho proposta por Christophe Dejours. Esse referencial envolve o estudo das condições de trabalho, da organização do trabalho e a insatisfação no trabalho para caracterizar os riscos e a degradação à saúde dos atores. Utilizamos também a noção de "cargas de trabalho" apresentadas por Laurrel e Noriega (1985) para complementar a compreensão do desgaste dos trabalhadores. As cargas de trabalho determinariam prejuízos à saúde dos trabalhadores 
expostos a esses elementos e estariam divididas entre cargas físicas, químicas, orgânicas, mecânicas, fisiológicas e psíquicas.

\section{Resultados}

A apresentação dos resultados terá início pelas informações quantitativas sobre AT oferecidas pela Comissão Interna de Prevenção a Acidentes (CIPA) da empresa estudada. De acordo com essas informações durante a safra que se estendeu pelos meses de abril a outubro de 2000 ocorreram 36 acidentes. Desses $78 \%$ não geraram afastamento, $11 \%$ determinaram afastamento inferior a 15 dias e $11 \%$ culminaram em afastamento superior a 15 dias.

A distribuição dos acidentes segundo o horário de ocorrência apresentou as quatro primeiras horas do turno matutino com a maior frequência de ocorrência de acidentes (58\%). Essa situação pode ser explicada por dois fatores: a troca de turnos e o ritmo acelerado de trabalho. A troca de turnos contribui respectivamente com $9,4 \%$ dos acidentes do turno matutino, $57 \%$ dos acidentes do turno vespertino e $40 \%$ dos acidentes do turno noturno. A adaptação das capacidades cognitivas e físicas do trabalhador poderia se encontrar dificultada no início dos turnos de trabalho em razão do ritmo intenso das atividades produtivas. Com a aceleração da produção, a “ação subversiva” (Dejours, 1997) aumentaria sua atividade e tenderia a um limite máximo de ação. A "noção de subversão" foi proposta por Dejours (1997, p. 13) para explicitar o modo como o trabalhador constrói "uma ordem psíquica por meio da qual ele tenta se livrar da ordem fisiológica”, ou seja, dos registros corporais que indicariam a sobrecarga de trabalho. Caso não seja reduzida a exigência por produtividade, a noção de subversão teria sua eficiência reduzida e consequentemente a probabilidade de ocorrência de ATs seria aumentada. A maior oferta de matéria-prima desde o início da manhã determinaria um esforço excessivo para a realização da atividade produtiva, que se aproximaria do limite máximo.

A oferta de matéria-prima aumentada motivaria a utilização de dois turnos de trabalhadores e dos equipamentos industriais de acionamento mecânico no período matutino. Esses equipamentos estabelecem a exposição dos trabalhadores a cargas mecânicas e exigências posturais inadequadas. Nos turnos vespertino e noturno, a utilização preponderante de equipamentos automáticos e a redução na oferta de cana-de-açúcar contribuem para a menor frequência de ATs.

A verificação da distribuição das lesões ocasionadas pelos ATs no corpo dos trabalhadores indica que $47 \%$ das lesões atingiram os membros superiores, $31 \%$ localizaram-se nos membros inferiores, os olhos foram lesionados em $18 \%$ dos episódios e o tórax foi atingido em $4 \%$ dos acidentes. As lesões dos membros superiores são mais comuns no setor de moagem e manutenção industrial em razão dos reparos e da movimentação de peças dos equipamentos fabris. No setor industrial de produção de açúcar são comuns episódios de queimaduras pela utilização de água quente e pressurizada proveniente do setor de caldeiraria para a limpeza do piso fabril e equipamentos industriais. As queimaduras atingem tanto membros inferiores quanto superiores e apresentam gravidade intermediária, pois o uso de Equipamentos de Proteção Individual (EPI) e as vestimentas reduzem a gravidade das lesões. Os ferimentos nos olhos têm destaque pela sua gravidade e por características do agente causador da lesão. Esses ATs foram gerados pelo contato com os olhos dos trabalhadores do bagaço da cana-de-açúcar disperso por rajadas de vento pelo ambiente. Em algumas ocasiões esse tipo de AT determinou incapacidade parcial permanente.

A observação do ambiente industrial e o contato com os integrantes da CIPA permitiram a identificação das seguintes "cargas de trabalho" (Laurrel e Noriega, 1985):

a) físicas: ruído excessivo, temperatura elevada, umidade constante, iluminação deficiente e água quente e pressurizada;

b) químicas: cal virgem, vapores dos processos produtivos e ácidos relacionados à preparação do caldo da cana-de-açúcar (ácido clorídrico e sulfúrico);

c) orgânicas: material particulado do bagaço de canade-açúcar (Bicinose) e população microbiana do bagaço de cana-de-açúcar (Bagaçoze);

d) mecânicas: escadas de acesso a equipamentos industriais, válvulas e equipamentos de acionamento manual, exigências ergonômicas e posturais intensas para o acionamento e a utilização de equipamentos mecânicos, má conservação de equipamentos industriais e de manutenção do parque fabril; 
e) fisiológicas: prolongamento da jornada de trabalho pela realização de horas extras; turnos noturnos e rotatividade mensal dos turnos de trabalho;

f) psíquicas: ritmo e intensidade de trabalho acelerados durante o turno matutino, intensificação das atividades na entressafra, perturbação do espaço fora do trabalho pela realização constante de horas extras durante a manutenção do parque industrial e incerteza quanto à permanência no emprego em safras posteriores.

A partir da apresentação das cargas de trabalho pode-se proceder a uma averiguação de alguns componentes que interatuam na degradação da saúde dos trabalhadores da indústria de transformação investigada. Em razão da escassez de pesquisas que discutem a saúde dos trabalhadores na produção de açúcar e álcool procedeu-se a discussão dos prejuízos à saúde determinados pelas cargas de trabalho, buscando referencias em atividades produtivas, tais como, a indústria petrolífera e a produção de baterias.

O ruído é descrito por Souza e colaboradores (2001) como um elemento que contribui para o desgaste ao quadro geral de saúde. Além dos prejuízos ao aparelho auditivo, os autores investigaram em trabalhadores petroleiros a associação entre a exposição ocupacional ao ruído e a ocorrência de hipertensão arterial. Os resultados indicaram associação positiva entre essas variáveis e que é possível "que o ruído, além de ser um fator de risco para a hipertensão arterial, concorre também para o seu agravamento" (Souza e col., 2001, p. 1486).

A exposição a compostos químicos oriundos de processo de transformação da matéria-prima é, de acordo com Barberino e colaboradores (2005), situação determinante para alterações hepáticas. Estudo realizado por esses autores indicou que a exposição a agentes químicos do processo produtivo determinava aos trabalhadores de uma refinaria petrolífera prevalência 3,56 vezes maior de alterações hepáticas do que a população em geral. Assim, deve-se considerar que na produção de açúcar e álcool os agentes químicos também estão envolvidos nos prejuízos às funções hepáticas.

Cordeiro e colaboradores (1996, p. 362) apontam que a exposição ocupacional ao chumbo apresenta prejuízos a saúde de trabalhadores que compreendem "disfunções da inteligência visual, desempenho visual-motor, formação de conceitos verbais, memória, humor, capacidade de associação verbal de conceitos, compreensão visual e atenção". Na indústria de transformação abordada nesta pesquisa encontrava-se um posto de trabalho onde a exposição aos fumos metálicos de chumbo era cotidiana. Esse posto de trabalho era denominado "chapiscador de moenda" e compreendia aplicar pingos de solda na moenda, durante o esmagamento da cana-de-açúcar, para aumentar sua rugosidade e, consequentemente, elevar a eficiência de extração do caldo da cana-de-açúcar. 0 chapiscador de moenda estava exposto à inalação de vapores metálicos de chumbo, tal como os soldadores de baterias investigados por Araújo e colaboradores (1999).

As cargas orgânicas são representadas pelas partículas oriundas do bagaço de cana-de-açúcar e pela população microbiana que se desenvolve nessas fibras vegetais. A inspiração cotidiana do material particulado disperso no ambiente pode ocasionar o depósito de partículas sólidas nas vias respiratórias, especialmente nos pulmões. As partículas depositadas nas cavidades pulmonares causariam irritações nas mucosas do sistema respiratório determinando um quadro clínico denominado "Bissinose" (Brasil, 1999). Williams e colaboradores (1988) indicaram que o contato com a população microbiana que contamina o bagaço de cana-de-açúcar poderia acarretar a forma aguda ou crônica da "Bagaçose”. Nessa afecção poderia ocorrer um quadro clínico de paracoccidioidomicose pulmonar, acarretando prejuízos às vias respiratórias pelo desenvolvimento de uma infecção fúngica nas cavidades pulmonares que contribuiria para a redução da captação de oxigênio.

A observação das cargas mecânicas de trabalho indica aspectos estruturais da planta industrial que contribuem para os prejuízos à saúde. Essa situação dificulta intervenções dos trabalhadores que reduziriam as solicitações osteomusculares e impede que ações proativas estabelecidas em treinamentos para a prevenção de acidentes possam ser implementadas. A inobservância da necessidade de remodelação de estruturas componentes da planta industrial tem como aspecto negativo desmobilizar os trabalhadores no desempenho de estratégias estabelecidas nos treinamentos de segurança, em razão do não reconhecimento de origens que modulam o desgaste ao trabalhador. Oliveira (2003, p. 7) afirma que a ausência de melhorias no ambiente e equipamentos que são indicadas pelos trabalhadores aumenta a dissensão entre os trabalha- 
dores e "os propósitos da empresa em relação ao engajamento voluntarioso e compromissado" na execução cotidiana dos pressupostos de segurança postados como referencias nas ações de treinamento.

A organização do trabalho em esquemas distintos do turno diurno expõe os trabalhadores "a maiores riscos de acidentes do trabalho" e intensifica a exposição "a estressores ambientais, que podem levá-los a incapacidade funcional precoce” (Moreno e col., 2003, p. 35). A perspectiva de desgaste ocupacional apresentada envolve cargas fisiológicas e psíquicas, pois, a rotatividade mensal dos turnos encontrada na empresa investigada interfere na cronobiologia dos indivíduos (Martino e col., 2005) e perturba as relações de sociabilidade fora do espaço do trabalho. Além disso, deve-se destacar a intensidade diferenciada de trabalho entre distintos turnos em virtude da variação da oferta de matéria-prima para processamento industrial. Desse modo, a intensificação do trabalho no turno diurno da empresa estudada contribui para a fadiga mental e hipersolicitação osteomuscular.

Após as discussões relacionadas às cargas de trabalho verificadas no parque industrial seguimos para a discussão do trabalho reconstituído pelo discurso do trabalhador durante a execução das entrevistas. A análise das entrevistas foi orientada pela proposta teórica dejouriana e possibilitou a compreensão de aspectos das Condições de Trabalho, Organização do Trabalho e Insatisfação apresentados abaixo:

\section{As condições de trabalho}

O calor excessivo é considerado situação desfavorável. Apesar de se encontrarem a distância do parque fabril, conforme legislação, as caldeiras contribuem para o aquecimento do ambiente de trabalho em razão da circulação dos ventos, pois não há limites físicos (paredes) entre os setores de transformação de matéria-prima e produção de energia elétrica e vapor. Em dias chuvosos, os funcionários ficam expostos a intempéries, devido à ausência de paredes entre as áreas externas e internas do parque fabril, havendo apenas a cobertura do telhado. Ocorreram também muitas queixas relacionadas ao contato com o bagaço de cana-de-açúcar, que serve para a alimentação das caldeiras. Outro item considerado desfavorável foi o barulho produzido pelas máquinas que, na opinião dos entrevistados, incomoda mesmo com o uso de protetores auriculares. Segundo eles, o barulho é significativo também nos ônibus de transporte para o trabalho. Esses veículos possuem ao menos duas décadas de utilização e possuem motores posicionados na parte dianteira da carroceria, ao lado do motorista, permitindo que o ruído se propague pelo interior do veículo. Esses elementos das condições de trabalho são ilustrativas dos apontamentos de Bragato e colaboradores (2008), que investigaram as ações compensatórias de empresas sucroalcooleiras diante dos prejuízos causados ao meio ambiente e à coletividade. Os autores destacaram que as ações sociais e educacionais são preponderantes nas práticas de gestão das empresas sucroalcooleiras e as ações relacionadas à saúde ocupam um plano secundário.

A produção de vapores não especificados devido à adição de ácido clorídrico e ácido sulfúrico durante o processo denominado preparação do caldo é entendido pelos trabalhadores como fonte de risco à saúde. 0 ácido clorídrico foi apontado pela CIPA da empresa como um componente de alto risco em situação de exposição ocupacional. Em caso de algum vazamento pode provocar queimaduras na pele. Porém, a maior preocupação apresentada pelos trabalhadores diz respeito ao vazamento do ácido clorídrico em forma gasosa. A inalação desse gás pode levar os trabalhadores a óbito. A CIPA apontou a dificuldade que pode encontrar para determinar a ocorrência de um vazamento em forma gasosa. Por ser invisível o vazamento gasoso é percebido apenas após o desmaio de algum trabalhador, e assim, já estaria configurada uma ocorrência de AT.

Destacam-se outros aspectos relativos à segurança, tais como, a falta de conservação de equipamentos industriais, falta de corrimão em escada metálica sobre a caixa de lodo e falta de passarela para acesso a controles de manuseio frequente o que determina aos trabalhadores posturas impróprias e risco de queda. Ainda, há exposição a choques elétricos pela presença de fiação para transmissão de energia elétrica debaixo do piso do parque fabril que é metálico e frequentemente está molhado devido a sua constante higienização com água corrente.

\section{A organização do trabalho}

O modo de organizar a atividade produtiva pode estar acarretando uma sobrecarga de trabalho e determinando a fadiga aos trabalhadores. Segundo informações da CIPA a cada sete dias de trabalho obtêm-se um dia 
de descanso. Esse modo de organização estaria estabelecido no acordo coletivo da categoria. Assim, ficam limitadas as horas de lazer, pois as folgas são usadas apenas para o descanso. Conforme aponta Silva (1999, p. 264) "para uma vida reduzida a tempo de trabalho, o tempo livre é quase inexistente". Há dificuldades para dormir, principalmente quando estão escalonados para trabalhar em turnos noturnos. Os hábitos alimentares também são alterados havendo em alguns casos dificuldades de adaptação aos horários anômalos de refeição. A forma de organização do trabalho em turnos interfere nos relacionamentos familiares e sociais havendo em alguns casos queixas das esposas em relação ao horário de trabalho dos maridos. A participação em atividades cotidianas da família e do espaço de sociabilidade fica comprometida pela rotatividade mensal dos turnos imposta pela organização do trabalho.

\section{A insatisfação no trabalho}

Os trabalhadores apontam o ritmo intenso de trabalho, as exigências ergonômicas para o acionamento de equipamentos, o barulho, o calor e a poeira como fontes de insatisfação. Os protetores auriculares oferecidos como EPI causavam irritação no pavilhão auditivo, algumas vezes, ocasionando pequenas lesões. A distância dos registros das mangueiras de água quente e pressurizada usadas para a limpeza do piso da fábrica causava incômodos e riscos à saúde dos trabalhadores. Caso o trabalhador precisasse soltar a mangueira rapidamente ocorreria o serpenteamento, ou seja, movimentos bruscos de difícil controle que espalhariam água em alta temperatura pela fábrica podendo atingir outros trabalhadores. Os trabalhadores relataram que já indicaram à CIPA a instalação de registros na extremidade das mangueiras, mas não foram atendidos. A CIPA alegou que para instalar estes registros seria necessária a substituição das mangueiras por outras que apresentassem maior resistência à pressão da água. Segundo a CIPA, a diretoria da empresa não permitiu esse investimento no equipamento de trabalho por considerá-lo oneroso. Essa posição foi confirmada pelo representante da diretoria da empresa aos pesquisadores na ocasião da devolutiva do trabalho de pesquisa realizado.

O horário avançado de saída dos turnos e a rotatividade mensal é fonte de insatisfação, pois inibe a participação dos trabalhadores em sistemas de educa- ção formal e profissionalizante. As rotações de turno determinariam a coincidência do horário escolar com o horário de trabalho na empresa. Ainda, apesar da disponibilidade de bolsas de estudo para a realização de cursos técnicos e superiores, os trabalhadores queixaram-se do difícil acesso às bolsas oferecidas. Os entrevistados apontaram a característica braçal e a intensidade de seu trabalho como uma barreira para o acesso às bolsas. Concluíram que os empregados ocupados em atividades nos escritórios poderiam flexibilizar o trabalho e estudar durante a jornada de trabalho. Também apontaram que a natureza intelectual do serviço dos escritórios contribuiria para uma formação intelectual ampliada, que facilitaria o acesso às bolsas de estudo que ocorre num processo seletivo similar ao vestibular.

Além das três categorias de análise das entrevistas propostas pela metodologia dejouriana para a compreensão do desgaste no trabalho, utilizaremos a investigação das concepções dos trabalhadores sobre ATs e a análise de algumas ocorrências de ATs descritas pelos trabalhadores para complementar o estudo de psicodinâmica do trabalho.

\section{As concepções dos trabalhadores sobre acidentes do trabalho}

As ações da empresa para inibir os ATs estariam sinalizando atividades individuais como fontes produtoras de agravos à saúde dos atores do trabalho. A análise das entrevistas referente à concepção dos trabalhadores sobre o que seria uma ocorrência de AT demonstra o desconhecimento dos trabalhadores sobre esse conceito. Na concepção dos trabalhadores, o acidente de trabalho estaria caracterizado quando houvesse ferimento tal ao indivíduo que causasse o afastamento do corpo ao trabalho (Dejours, 1992).

Nesse sentido, ocorrências que não geram o impedimento das atividades produtivas não são considerados acidentes na concepção dos trabalhadores. Não há, então, a iniciativa dos trabalhadores em solicitar o registro da Comunicação de Acidente do Trabalho (CAT) contribuindo para a subnotificação dos ATs. Quando algum acidente acontece o atendimento médico/hospitalar é realizado no ambulatório médico da própria empresa. Desse modo, só é notificado ao INSS os ATs que o ambulatório médico da empresa não tem possibilidade de acolher, em função da demanda de gravidade. 
A apresentação das entrevistas a seguir ilustra o desconhecimento do conceito de AT pelos trabalhadores. Em resposta à questão Já sofreu algum AT?, obtivemos as seguintes respostas:

Não; já tive pequenos machucados. Nunca nada grave. Machucados pequenos émuito comum, principalmente na época de reparos [entressafra]. Já durante a safra é mais difícil, quase não acontece nada.

Não. Acontecem ferimentos leves, mas não geram afastamentos.

Além do desconhecimento do conceito de AT prevalece a "teoria do ato inseguro" (Carmo e col., 1997) entre os entrevistados. As atividades de treinamento e desenvolvimento pessoal realizadas pelo Departamento de Recursos Humanos para o cumprimento de metas para a obtenção de certificações ISO podem contribuir para a disseminação da teoria do ato inseguro e para o desconhecimento do conceito de AT. A curto prazo, a atuação do Departamento de Recursos Humanos seria conveniente à empresa por subtrair-lhe a responsabilidade pelos episódios de ATs e reduzir o número absoluto de acidentes de trabalho em razão da subnotificação. Essa situação causaria uma falsa impressão de segurança na empresa e de eficiência das técnicas preventivas empregadas pelo Serviço Especializado em Segurança e Medicina do Trabalho (SESMT). Porém, a longo prazo, os conceitos disseminados pelo treinamento e desenvolvimento de pessoal reduziriam a eficiência do SESMT, pois, se o acidente é sempre decorrente da falha do trabalhador, não haveria possibilidades de instauração de técnicas preventivas ou mudanças na estrutura da unidade produtiva. Segundo a lógica operante do ato inseguro qualquer medida que visasse à segurança no trabalho seria boicotada indiretamente pelos trabalhadores por meio de ações inseguras.

Diante do questionamento sobre como ocorreriam os ATs, assim se manifestaram os entrevistados:

A maior parte acontece por descuido dos caras, eu acho.

Acho que os acidentes acontecem a maioria por falta de cuidado e atenção das pessoas.

Acho que os acidentes de trabalho acontecem por descuido do cara. Ele pensa: não vou usar o cinto, é rapidinho. Aí é quando acontece.
Para mim acontece muito acidente por falta de orientação do pessoal.

Acho que a maioria dos acidentes acontece por falha humana, do grupo, sua mesmo ou de um amigo. $\varepsilon$ descuido que acaba acontecendo.

Acho que a maioria dos acidentes acontece por descuido, é o momento de bobeira.

A difusão de técnicas preventivas centradas na atividade pessoal, ou seja, no ato inseguro do trabalhador determinaria uma estratégia de prevenção incompleta pela organização do trabalho em razão da limitação de investimentos necessários ou porque o risco e suas manifestações são negligenciadas (Dejours, 1992).

Carmo e colaboradores (1997), ao verificar estudos sobre a ocorrência de ATs, apontam que na maioria desses estudos os acidentes tem suas causas atribuídas à realização de atos inseguros por parte dos trabalhadores. Para esses autores, a ênfase na busca de responsabilidades individuais é tendenciosa e deveria ser criticada pela produção da consciência culposa, baseada no pressuposto falseado de que o trabalhador detém o controle do processo e da organização do trabalho. Ainda segundo esses autores, alguns obstáculos impedem o progresso de medidas de prevenção relacionadas ao AT: a identificação de causas confundida com a identificação de culpados; a inibição indireta das ações preventivas e a ênfase dada aos comportamentos humanos. Desse modo, o cerceamento de informações relativas à ocorrência de ATs paralisariam as atividades de prevenção e elucidação de acidentes que seria responsabilidade da CIPA.

Após a revisão das concepções dos trabalhadores sobre acidentes apresentamos o relato de três ocorrências de ATs e as consequentes discussões.

\section{Relato de ocorrência de AT número 1:}

Já sofreu algum acidente de trabalho? Não, mas eu já vi. O meu colega cortou o joelho, não, a perna outro dia. É que o pessoal tem mania de cortar as botas porque assim não ficava muito pesada para andar, principalmente quando molha. Aí ele bateu no ferro da escada quando escorregou e cortou a perna. Se não tivesse cortado [a bota] não iria acontecer. Mas depois disso, os chefes ficaram bravos e falou pra ninguém mais cortar as botas. Todo mundo aprendeu e ninguém mais corta agora. 
Modificando o EPI para facilitar sua locomoção o trabalhador buscou atender ao ritmo intenso de trabalho. Por todo o dia o chão é lavado e, quando trabalham no piso da fábrica, o calçado constantemente está molhado. Quando é necessária a locomoção pelas escadas o risco de um trabalhador escorregar é plausível, pois o piso da escadaria é escorregadio apesar de se encontrar de acordo com as especificações técnicas. Caso o trabalhador não houvesse cortado o cano da bota o corte na perna seria evitado, porém, o escorregão na escadaria não. Assim, a responsabilidade pela ocorrência do acidente foi transferida para o trabalhador - ato inseguro - e negligenciou-se o risco ocupacional representado pelo piso escorregadio das escadas e a presença de superfície corto-contundente. Em nossa concepção, ao alterar o EPI, o trabalhador não negligenciou a segurança cometendo um ato inseguro; buscou atender à demanda por produtividade e evitar um maior desgaste físico na execução da atividade laborativa. Dessa forma, consideramos que a ênfase no fator humano (Dejours, 1999) nas situações de investigação de AT incorre no equívoco de "interpretar todos os comportamentos ineficazes em face da racionalidade teleológica e estratégica como falhas humanas, quando se trata, muito frequentemente, de condutas racionais e não de erros" (Dejours, 1999, p. 70).

\section{Relato de ocorrência de AT número 2:}

Já sofreu algum acidente do trabalho? Sim, foi em maio deste ano (200o). Eu queimei a perna com água quente. Eu estava com a mangueira na centrífuga, lá a água fica mais ou menos a $100{ }^{\circ} \mathrm{C}$; eu abri tudo e a mangueira escapou e espirrou [água] na minha perna. Eu também estava no lugar errado, fiquei bem de frente da torneira. Se estivesse de lado [...] acho que a mangueira não estava bem fixada.

Qual a hora aproximada da ocorrência de AT? Início, meio ou fim do turno? Foi umas 8 h3o. Na hora vim aqui no ambulatório, tive os primeiros socorros, retiraram a pele e cobriu. Aífui para um médico na cidade. $\mathrm{O}$ acidente deixou sequelas? Não, só ficou manchado. Ficou afastado do trabalho após o acidente? Fiquei afastado um mês. Só que no décimo sexto dia já tava bom, mas aí já tinha entrado no INSS e os médicos lá não queriam me liberar. Eu ia lá pedir pra voltar. Como você sentiu a situação do afastamento? Dava tédio ficar parado. Desde pequeno sou acostumado a trabalhar. Na função que desempenhava era obrigatório o uso de EPI? Era. Você fazia uso do EPI no momento do acidente? $\varepsilon u$ usava mas não tinha como o EPI evitar.

Esse relato ilustra com clareza uma inadequação no instrumento de trabalho. Mesmo assim, o trabalhador relata que se não estivesse em frente à mangueira não haveria ocorrido o AT, destacando a consciência culposa pelo "ato inseguro" (Carmo e col., 1997) do trabalhador. Vale ressaltar, que mesmo se o trabalhador não estivesse em frente à mangueira a falha do instrumento de trabalho teria ocorrido. Mesmo não havendo vítimas estaria configurado um incidente potencialmente grave. Esse trabalhador lança mão da racionalização do acidente (Dejours, 2001), encobrindo uma possível deficiência do instrumento de trabalho. A racionalização deve ser aqui entendida como "uma defesa psicológica que consiste em dar a uma experiência, a um comportamento ou a pensamento reconhecidos pelo próprio sujeito como inverossímeis uma aparência de justificação" (Dejours, 2001, p. 72). A internalização da consciência culposa revela a dominação dos trabalhadores pelo discurso organizacional, que fragmenta os trabalhadores em espaços organizacionais individualizados e dificulta a mobilização coletiva em prol de negociações coletivas por melhores condições de trabalho.

\section{Relato de ocorrência de AT número 3:}

Já sofreu algum acidente do trabalho? Já.Sem afastamento, foi queimadura. Aconteceu algum outro? Duas vezes no ano passado com a mangueira. In diquei melhorias na mangueira, uma válvula, mas não fizeram nada. $O$ supervisor não dá atenção para as sugestões dos trabalhadores. Mais gente se machucou na mangueira.

Este relato ilustra o risco real de acidente quando o trabalhador está ocupado na limpeza das instalações industriais utilizando uma mangueira com água fervente e pressurizada. Apesar da recomendação para a adequação da mangueira foi desconsiderada a medida proativa indicada pelo trabalhador. Os supervisores da organização do trabalho negligenciaram o conhecimento dos trabalhadores sobre as situações de risco e possíveis ações preventivas para evitar a ocorrência de AT. Nesse caso, a negligência relacionada aos instrumentos de trabalho demonstra a orientação organizacional de maximizar a lucratividade pela precarização 
dos investimentos nas instalações industriais e das condições de exploração da mão-de-obra. Essa situação ilustra que, para a empresa estudada, a segurança no trabalho é discutida primordialmente em termos de valores financeiros, renegando os possíveis agravos à saúde dos trabalhadores.

\section{Considerações Finais}

A delimitação das cargas de trabalho que compõem o processo de desgaste à saúde nas atividades industriais da agroindústria canavieira, apresenta-se como ação orientada para reconhecimento dos processos de agravo à saúde que atingem os trabalhadores. Entretanto, para a compreensão do modo como se relacionam para a produção do desgaste à saúde é necessário abordar os aspectos concernentes às condições de trabalho e sua organização.

As condições de trabalho expõem seus agentes a exigências posturais e de dispêndio de força muscular excessivas em razão do acionamento mecânico de equipamentos industriais e da utilização de instrumentos de trabalho. As dificuldades geradas para o controle dos equipamentos industriais, além de ocasionar irritabilidade e lesões musculares, proporcionam riscos de acidentes por exigir do trabalhador adaptações dos sistemas de acionamento configurando-se potencialmente como risco.

A ausência de treinamento técnico que apresentasse a totalidade do funcionamento dos equipamentos industriais aos trabalhadores envolvidos na manutenção e limpeza industrial revelou uma conjuntura organizacional em que as situações de risco são negligenciadas. Scopinho (2000, p. 105), ao investigar as políticas organizacionais de treinamento dos trabalhadores industriais de empresas sucroalcooleira, destacou que essas práticas restringissem a "difundir e harmonizar as metas organizacionais e [...] envolver a todos na perseguição dos objetivos comuns”. Nessa perspectiva, o treinamento negligencia a possibilidade de instrumentalizar o trabalhador para o enfrentamento de fontes de risco ocupacional. Evidencia-se também que a descaracterização das fontes potenciais de acidentes em razão da inobservância dos apontamentos dos trabalhadores sobre as situações de risco é parte dessa conjuntura de negligências organizacionais ilustrada pelos acidentes com as mangueiras de água fervente e pressurizada.
A imposição de uso de equipamentos de proteção individual, considerados inadequados pelos trabalhadores, articula-se com as dificuldades existentes para a obtenção das bolsas de estudo orientadas para a progressão organizacional de modo pejorativo para o trabalhador. Dessa articulação emergem cargas psíquicas de trabalho em razão da subordinação da saúde e da subjetividade dos trabalhadores à maximização dos lucros e ao assujeitamento humano como objeto da relação capital/trabalho.

Subjugado às relações de poder no trabalho, sua ação produtiva é atravessada pelo empenho organizacional em destinar ao trabalhador a responsabilidade pelos agravos à sua saúde ocasionados pelos acidentes. Dessa forma, o reconhecimento do nexo causal entre as condições de execução da atividade produtiva e a ocorrência de acidentes do trabalho fica preterida e a suposição do Ato Inseguro do trabalhador encobre a violência constituída discursivamente pela organização do trabalho.

\section{Referências}

ALESSI, N. P.; NAVARRO, V. L. Saúde e trabalho rural: o caso dos trabalhadores da cultura canavieira na região de Ribeirão Preto, São Paulo, Brasil. Cadernos de Saúde Pública, Rio de Janeiro, v. 13, p. 111-121, 1997. Suplemento 2.

ARAÚJO, U. C.; PIVETTA, F. R.; MOREIRA, J. C. Avaliação da exposição ocupacional ao chumbo: proposta de uma estratégia de monitoramento para prevenção dos efeitos clínicos e subclínicos. Cadernos de Saúde Pública, Rio de Janeiro, v. 15, n. 1, p. 123-131, 1999.

BARBERINO, J. L. et al. Alterações hepáticas em trabalhadores de uma refinaria de petróleo e em uma população de referência no Estado da Bahia, Brasil. Revista Panamericana de Salud Pública, v. 17, n. 1, p. 30-37, 2005.

BLEGER, J. Temas de psicologia: entrevistas e grupos. São Paulo: Martins Fontes, 1990.

BRAGATO, I. R. et al. Produção de açúcar e álcool vs. responsabilidade social corporativa: as ações desenvolvidas pelas usinas de cana-de-açúcar frente às externalidades negativas. Gestão e Produção, São Carlos, v. 15, n. 1, p. 89-100, 2008. 
BRASIL. Ministério da Saúde. Relação de doenças relacionadas ao trabalho. Brasília, DF, 1999.

Disponível em: <www.cnbcut.com.br/social/ lisdoenc1.htm>. Acesso em: 17 ago. 2002.

BRASIL. Ministério da Previdência e Assistência Social. Estatísticas de acidentes do trabalho. Brasília, DF, 2002. Disponível em: <http://creme. dataprev.gov.br/scripts7/Netuno.exe>. Acesso em: 25 jan. 2006.

BRASIL. Ministério da Agricultura, Pecuária e Abastecimento. Departamento de cana-de-açúcar e agroenergia. Brasília, DF, 2007. Disponível em: <www.agricultura.gov.br/pls/portal/docs/PAGE/ MAPA/ESTATISTICAS/PRODUCAO/PROD_CANA_ ACUCAR_ALCOOL_MENSAL.PDF $>$. Acesso em: 7 jan. 2007.

CARMO, J. C. et al. Acidentes do trabalho. In: MENDES, R. Patologia do trabalho. São Paulo: Atheneu, 1997. p. 431-453.

CORDEIRO, R. et al. Distúrbios neurológicos em trabalhadores com baixos níveis de chumbo no sangue: II - disfunções neurocomportamentais. Revista de Saúde Pública, São Paulo, v. 3o, n. 4, p. 358-363, 1996.

DEJOURS, C. A loucura do trabalho: estudo de psicopatologia do trabalho. São Paulo: Cortez: Oboré, 1992.

DEJOURS, C. Psicodinâmica do trabalho: contribuições da Escola Dejouriana à análise da relação prazer, sofrimento e trabalho. São Paulo: Atlas, 1994.

\section{DEJOURS, C. Repressão e subversão em} psicossomática. Rio de Janeiro: Zahar, 1997.

DEJOURS, C. O fator humano. Rio de Janeiro: FGV, 1999.

DEJOURS, C. A banalização da injustiça social. Rio de Janeiro: FGV, 2001.

GOMES, J. R.; FISCHER, F. M.; BEDRIKOW, B. Trabalho da criança e do adolescente no corte da cana-de-açúcar. Revista Brasileira de Saúde Ocupacional, São Paulo, v. 1, n. 26, p. 2-27, 2001.

LAURREL, A. C.; NORIEGA, M. Processo de produção e saúde: trabalho e desgaste operário. São Paulo: Hucitec, 1985.
MARTINO, M. M. F.; SILVA, C. A. R.; MIGUEZ, S. A. Estudo do cronótipo de trabalhadores em turnos. Revista Brasileira de Saúde Ocupacional, São Paulo, v. 30, n. 111, p. 17-24, 2005.

MORENO, C. R. C.; FISCHER, F. M.; ROTENBERG, L. A saúde do trabalhador na sociedade 24 horas. São Paulo em Perspectiva, São Paulo, v. 17, n. 1, p. 34-46, 2003.

OLIVEIRA, J. C. Segurança e saúde no trabalho: uma questão mal compreendida. São Paulo em Perspectiva, São Paulo, v. 17, n. 2, p. 3-12, 2003.

PINHEIRO, S. A.; RUFFINO NETTO, A. Saúde do trabalhador II: o processo de trabalho e as cargas laborais no pátio de uma destilaria de álcool. Revista Brasileira de Saúde Ocupacional, São Paulo, v. 22, n. 84, p. 41-49, 1994.

RUMIN, C. R. Trabalho rural e saúde: um estudo das condições de trabalho e sua relação com a saúde dos cortadores de cana-de-açúcar do município de Pacaembu (SP). 2004. Dissertação (Mestrado em Ciências Médicas) - Faculdade de Medicina de Ribeirão Preto da Universidade de São Paulo, Ribeirão Preto, 2004,

SILVA, M. A. M. Errantes do fim do século. São Paulo: Unesp, 1999.

SCOPINHO, R. A. Qualidade total, saúde e trabalho: uma análise em empresas sucroalcooleiras paulistas. Revista de Administração Contemporânea, Curitiba, v. 4, n. 1, p. 93-112, 2000.

SOUZA, N. S. S.; CARVALHO, F. M.; FERNANDES, R. C. P. Hipertensão arterial entre trabalhadores de petróleo expostos a ruído. Cadernos de Saúde Pública, Rio de Janeiro, v. 17, n. 6, p. 1481-1488, 2001.

TEIXEIRA, M. L. P.; FREITAS, R. M. V. Acidentes do trabalho rural no interior paulista. São Paulo em Perspectiva, São Paulo, v. 17, n. 2, p. 81-90, 2003.

THOMAZ JÚNIOR, A. Por trás dos canaviais, os "nós" da cana: a relação capital x trabalho e o movimento sindical dos trabalhadores na agroindústria canavieira paulista. São Paulo: Annablume: Fapesp, 2002.

\section{UNIÃO DA AGROINDÚSTRIA CANAVIEIRA.}

Estatística da produção. Disponível em: <http://www. portalunica.com.br/portalunica/?Secao=referência $>$. Acesso em: 5 jan. 2007. 
WILLIAMS, M.; CLARKE DE MARTIN, M.;

QUINZADA, M. O. La población microbiana del

bagazo en los ingenios azucareros de la República de

Panamá. Scientia, Panamá, v. 3, n. 2, p. 23-29, 1988.

Recebido em: 19/09/2007

Reapresentado em: 23/06/2008

Aprovado em: 25/06/2008 